\title{
Biochar from lab-scale pyrolysis: influence of feedstock and operational temperature
}

\author{
Giovanni Ferraro ${ }^{1,2} \cdot$ Giuditta Pecori $^{1} \cdot$ Luca Rosi $^{1,2,3} \cdot$ Lorenzo Bettucci $^{3} \cdot$ Emiliano Fratini $^{1,2}$ (D) David Casini $^{3}$. \\ Andrea Maria Rizzo ${ }^{3}$. David Chiaramonti ${ }^{3,4}$
}

Received: 16 October 2020 / Revised: 5 January 2021 / Accepted: 12 January 2021

(C) The Author(s) 2021

\begin{abstract}
Biochar properties are highly dependent on the feedstock type and operational conditions during thermochemical processing, in particular slow pyrolysis. To clarify this aspect, nine biochars were produced by pyrolyzing in a macro TGA at 400, 550, and $650{ }^{\circ} \mathrm{C}$ three different decorticated and chopped biomasses. The studied biomasses are representative of conifer (black pine) and deciduous (poplar and willow) woods. Biochar surface area, size, and shape of pores were investigated by means of nitrogen adsorption isotherm, Hg porosimetry, and electron microscopy. The results indicate that biochars with high surface area can be obtained at high temperature, especially starting from pine feedstock. Regarding porosity, micro-pores (1-10 nm) are not remarkably affected by the starting feedstocks, while macro-pores $(>10 \mathrm{~nm})$ are strictly connected with the morphology of the starting wood. More than the surface area, we found a strong correlation between the chemical composition (elemental composition and FTIR) of the biochars and their retention and release capacity of ions (cation exchange capacity, CEC). The trend in the CEC, determined via coupled approach by spectrophotometric and ion chromatography, reveals that the increase in the processing temperature has the effect of reducing the number of functional groups able of exchanging the cations with the equilibrium solution. This work represents a step forward in the characterization of the char produced by pyrolysis of biomass thanks to the development of a multi-technique approach allowing to obtain a structure-property correlation of the biochars. Our results and experimental approach can help in the optimization of the parameters used in the preparation of these materials.
\end{abstract}

Keywords Biochar · Lab-scale pyrolysis · Porosity · Cation exchange capacity (CEC) · Lignocellulosic biomass · Pyrolysis temperature $\cdot$ Water retention

\section{Introduction}

Giovanni Ferraro and Giuditta Pecori contributed equally to this work.

Luca Rosi

luca.rosi@unifi.it

Emiliano Fratini

emiliano.fratini@unifi.it

1 Department of Chemistry "Ugo Schiff", University of Florence, Via della Lastruccia, 3-13, I-50019 Sesto Fiorentino, Italy

2 Consorzio per lo Sviluppo dei Sistemi a Grande Interfase (CSGI), University of Florence, Via della Lastruccia, 3, I-50019 Sesto Fiorentino, Italy

3 RE-CORD, Renewable Energy COnsortium for R\&D, Viale Kennedy 182, 50038, Scarperia e San Piero, Florence, Italy

4 Dipartimento Energia "Galileo Ferraris", Politecnico di Torino, Corso Duca degli Abruzzi 24, I-10129 Torino, Italy
Biochar is the carbon-rich product obtained by heating lignocellulosic biomass in the absence of (or with very limited) oxygen at process temperatures normally in the range of $400-600{ }^{\circ} \mathrm{C}[1]$. The word "biochar" is a neologism that combines the words "bio" (from Greek, life) and "char" (from English, charcoal, to distinguish from fossil coal). The definition was proposed by IBI (International Biochar Initiative) and specifically indicates that this material is used in the field of agricultural and environmental protection [2], and then it was extended to many other applications far beyond agriculture, as flue gas and water treatment (most of these uses are well known and fully mature at industrial scale since decades). Currently, several thermochemical technologies such as pyrolysis, gasification, and hydrothermal conversion are employed to produce biochar. Various types of biomass can be used as feedstock, including agricultural and forestry 
products and by-products, such as wood chips, straw, nut shells, rice hulls, tree bark, wood pellets, and switch grass; agro-industrial and biorefining by-products, as sugarcane bagasse and straw, paper sludge, and cellulose pulp; animal wastes, such as chicken litter, dairy and swine manure; and sewage sludge. Producing biochar from lignocellulosic biomass, especially forest and agricultural wastes, represents an excellent way to valorize residues into bio-based materials [2].

Biochar is composed of carbon $(\mathrm{C})$, hydrogen $(\mathrm{H})$, oxygen $(\mathrm{O})$, nitrogen $(\mathrm{N})$, phosphorus $(\mathrm{P})$, sulfur $(\mathrm{S})$, and ash in different proportions. Its properties extensively change depending on the type of feedstock (wood structure, chemical composition, ash content, particle size), the process conditions (temperature, time, oxidative conditions), the pre-treatment (drying, crushing), and post-treatment steps (for instance, activation methods if the final product is activated carbon) [3]. The presence of pores of different diameter ranging from less than $2 \mathrm{~nm}$ up to more than $10 \mu \mathrm{m}$ [1] in biochar provides high adsorptive capacities to this material and allows the adsorption of small molecules, such as gases and solvents [1]. Thus, biochar is an effective material for different applications, including waste management, soil remediation, and carbon sequestration [4-7]. Furthermore, biochar has been reported to improve soil fertility and quality by raising soil $\mathrm{pH}$, and increasing moisture holding capacity and plant-available water $[8,9]$. The surface chemistry of biochar (e.g., the ratio hydrophilic/hydrophobic domains) is another parameter that could affect the ability to retain and release water [1]. Suliman et al. demonstrated that the increase in the oxygen functional groups on the surface of biochar enhances the water-holding capacity of the material [3]. Finally, it is proved that the use of biochar as soil amendment significantly decreases soil bulk density, promotes the soil organic matter [10], attracts more beneficial fungi and microbes [11], and retains nutrients (potassium, phosphorus, zinc, calcium, and copper) $[12,13]$. It is therefore of great interest to study biochar's ability in cations retention and release: cation exchange capacity (CEC), is defined as the total amount of exchangeable cations that the soil can adsorb. In the soil, cations such as $\mathrm{Ca}^{2+}, \mathrm{Mg}^{2+}, \mathrm{K}^{+}, \mathrm{Na}^{+}$, $\mathrm{H}^{+}, \mathrm{Al}^{3+}, \mathrm{Fe}^{3+}$, and $\mathrm{Mn}^{2+}$ are retained both by the clay, negatively charged for the presence of hydroxyl groups present in the phyllosilicates, and organic matter through electrostatic forces. In the case of organic matter, the cation exchange capacity is mainly due to the presence of carboxyl groups. The cations in the soil are easily exchangeable with the equilibrium aqueous phase and can be adsorbed by the roots of the plants [14].

Several methods have been proposed for the determination of the cation exchange capacity of biochar, depending on the particular feedstock and production technique employed [15-17]. In addition, potential sources of error in CEC determination could arise from the biochar microporous structure, which can prolong the equilibration time, and from its intrinsic hydrophobicity, which can cause poor wetting of the sample with a global underestimation of the CEC value. The presence of base cations, such as those linked to carbonates and silicates, can interfere with the sum of exchangeable base cations giving an overestimation of CEC [18]. For these reasons, Munera-Echeverri et al. [19] tried to modify and critically assess different steps in the ammonium acetate $\left(\mathrm{NH}_{4} \mathrm{OAc}\right)$ method (pH 7). They introduced a pretreatment step of biochar, using diluted hydrochloric acid, to decrease biochar $\mathrm{pH}$ to near neutral, so that $1 \mathrm{M} \mathrm{NH}_{4} \mathrm{OAc}$ effectively buffers the biochar suspension $\mathrm{pH}$ at 7 . This allows the $\mathrm{CEC}$ of all biochars to be determined at $\mathrm{pH} 7$, which is crucial for biochar comparison. Skipping the pretreatment step causes a major overestimation of the CEC of biochar. Moreover, they observed that isopropanol may not penetrate the smallest pores of some biochars and therefore other liquid compounds are required to fully remove excess $\mathrm{NH}_{4} \mathrm{OAc}$.

In this study, the macro- and micro-porosity of nine biochars, produced by pyrolysis at different temperatures $\left(400{ }^{\circ} \mathrm{C}, 550{ }^{\circ} \mathrm{C}\right.$, and $650{ }^{\circ} \mathrm{C}$ ) of both softwood (black pine) and hardwood (poplar and willow) were investigated. The combined use of nitrogen adsorption isotherm, $\mathrm{Hg}$ porosimetry, and electron microscopy was proposed to investigate the relationships between feedstock, pyrolysis temperature, and physico-chemical properties of the obtained char. Furthermore, the retention and release capacity of ions was quantified via CEC using the ammonium acetate method, as usually determined in soil analysis and adapted for biochar. The final goal was to contribute into the understanding of the correlation between the chemical composition and micro-/macro-structure of the char with its retention/release capacity.

To the best of our knowledge, this work represents a step forward in the biochar field since previous works report only a partial picture of the problem. Indeed, some articles investigated the properties of biochar produced from various feedstocks at different pyrolysis temperatures in terms of biochar's water retention [20] or connected to its mechanical properties [21]. Other authors focused their attention only on the CEC obtained on different biochars $[15,18,19]$.

\section{Material and methods}

\subsection{Biochar production}

Biochar samples were produced from woody feedstocks: black pine, poplar, and willow woods $\sim 15 \mathrm{~cm}$ length and 1$2 \mathrm{~cm}$ diameter were peeled, milled, and sieved at dimension of $4 \mathrm{~mm}$ using a Retsch SM 300 mill. The biomass was not pretreated before pyrolysis. Pyrolysis was performed in a macro TGA (LECO TGA 701) under nitrogen flow $(10 \mathrm{~L} / \mathrm{min})$ at a heating rate of $20^{\circ} \mathrm{C} / \mathrm{min}$, maintaining a 2 -h thermal plateau 
at $400{ }^{\circ} \mathrm{C}, 550{ }^{\circ} \mathrm{C}$, or $650{ }^{\circ} \mathrm{C}$. All biochars were prepared starting from $2 \pm 0.1 \mathrm{~g}$ of feedstock and using a large TGA ceramic crucible (volume $20 \mathrm{~mL}$ ). All samples were characterized in terms of elemental analysis, surface area, pore size distribution, and functional groups and tested to determine the retention and release capacity of ions via CEC. The appearance of the samples at the different production steps is reported in Fig. 1.

The samples will be referred as black pine (BP), poplar (P), and willow (W).

\subsection{Chemicals}

Isopropanol (98\%), potassium chloride $(\mathrm{KCl}, 99 \%)$, ammonium acetate $\left(\mathrm{NH}_{4} \mathrm{OAc}, 98 \%\right)$, hydrochloric acid $(\mathrm{HCl}, 37 \%)$, sulfuric acid $\left(\mathrm{H}_{2} \mathrm{SO}_{4}, 95-97 \%\right)$, sodium nitroprusside $(99 \%)$, and sodium salicylate $(99.5 \%)$ were purchased from SigmaAldrich and used as received without further purification.

\subsection{Elemental analysis (CHNS-O-ashes)}

Elemental analysis was performed using the instrument LECO TruSpec CHN equipped with the TruSpec S modulus on $60-80 \mathrm{mg}$ of crushed samples by a routine flash combustion procedure. Each sample was measured three times. The instrument was calibrated with a phenylalanine standard for the CHN modulus while coal was used as standard for the $\mathrm{S}$ modulus. The oxygen $(\mathrm{O})$ content was inferred by difference as $\mathrm{O}=100-(\mathrm{C}+\mathrm{N}+\mathrm{H}+\mathrm{S}+\mathrm{ash})$. The ash content was measured using thermogravimetric analysis (LECO TGA 701) after moisture removal $\left(105{ }^{\circ} \mathrm{C}\right.$ under air flux $\left.5 \mathrm{~L} / \mathrm{min}\right)$ and oxidative heating at $550{ }^{\circ} \mathrm{C}(7 \mathrm{~L} / \mathrm{min}$ oxygen flow $)$ according to the procedure UNI EN ISO 18122. Volatile components were quantified heating the samples at $900{ }^{\circ} \mathrm{C}$ under nitrogen flow (10 L/min) for $7 \mathrm{~min}$ (procedure UNI EN ISO 18123).

\subsection{Surface area and pore size distribution}

Surface area was determined by $\mathrm{N}_{2}$ adsorption isotherms (BET) in a Quantachrome NOVA 2200E instrument. Experiments were performed on $60 \mathrm{mg}$ samples preliminarily dried at $200{ }^{\circ} \mathrm{C}$ for $48 \mathrm{~h}$. All measurements were performed after degassing $\left(200^{\circ} \mathrm{C}\right.$ for $\left.24 \mathrm{~h}\right)$. Micro-porosity was estimated using the DFT approach on BET isotherms as reported elsewhere [22], while the macro-porosity of biochar samples produced at $550{ }^{\circ} \mathrm{C}$ was also evaluated using a PoreMaster- 60 $\mathrm{Hg}$ porosimeter.

\subsection{Scanning electron microscopy}

SEM experiment was conducted using a $\Sigma$ IGMA highresolution scanning electron microscope (Carl Zeiss) based on the GEMINI column which features a high-brightness Schottky field emission source, beam booster, and in-lens
Fig. 1 Black pine (panel a), poplar (panel b), and willow (panel c) woods before (top) and after (middle) the milling process. Biochars obtained after the pyrolysis are shown in the bottom line
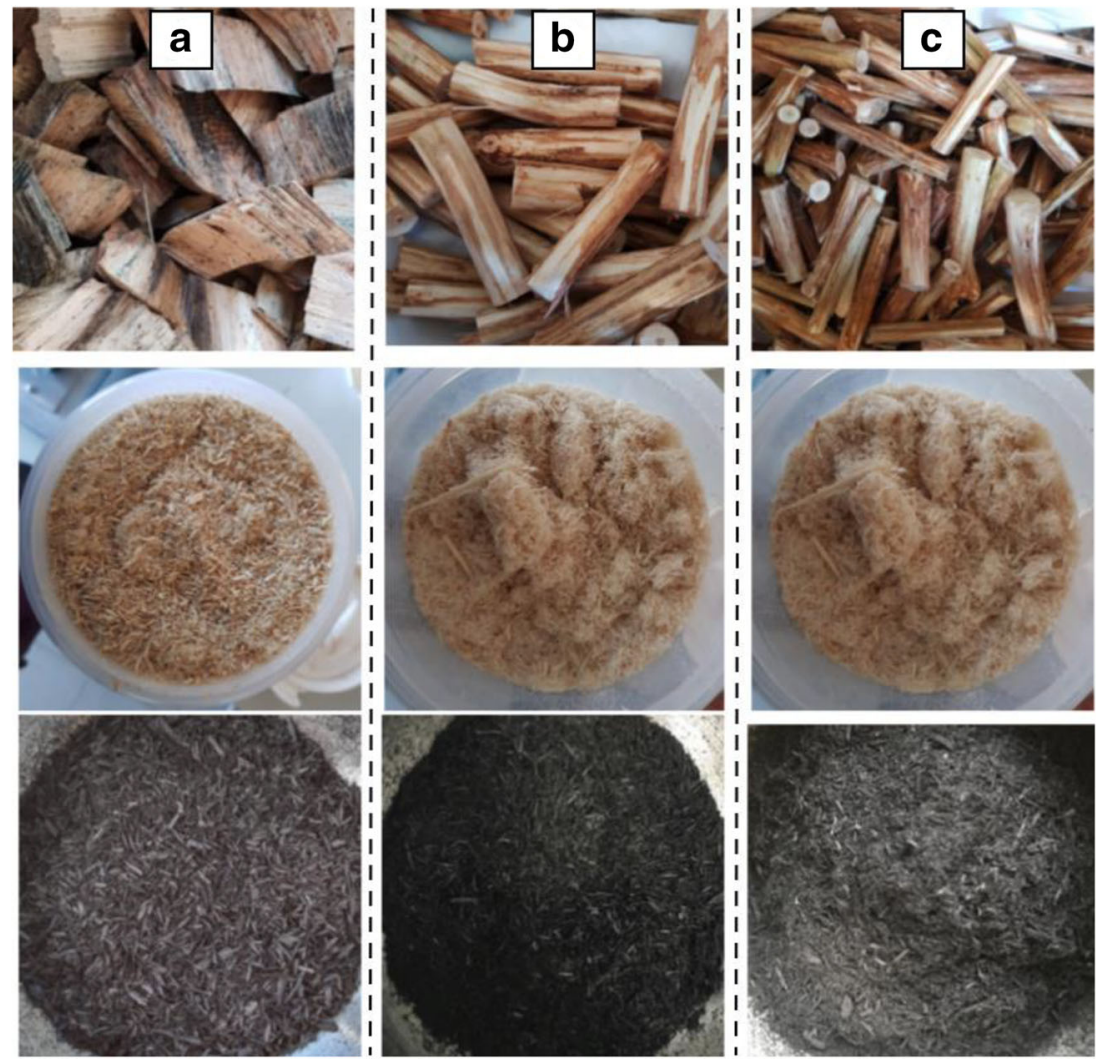
secondary electron detector. Measurements were conducted on uncoated samples with an acceleration potential of $2 \mathrm{kV}$ and at a working distance of about $3 \mathrm{~mm}$.

\subsection{Infrared spectroscopy}

Infrared spectroscopy was performed by a SHIMADZU IRTracer-100 spectrometer. Data were collected at room temperature in attenuated total reflectance (ATR) mode. The optical resolution was $4 \mathrm{~cm}^{-1}$, and the spectral range investigated was from 600 to $4000 \mathrm{~cm}^{-1}$. A total of 45 scans was averaged to have an acceptable signal-to-noise ratio.

\subsection{Ion chromatography}

The ion chromatograph used for the analysis was a Dionex DX120 equipped with a Dionex Ion Pac CG12A $(4 \times 50 \mathrm{~mm})$ guard column and a Dionex Ion Pac CS12A $(4 \times 250 \mathrm{~mm})$ separation column (eluent: $\mathrm{H}_{2} \mathrm{SO}_{4} 22.5 \mathrm{mN}$ ). This experimental setup allows to obtain a good detection of ammonium if compared to other cationic species with similar retention times $\left(\mathrm{Na}^{+}\right.$ and $\mathrm{K}^{+}$). However, in order to eliminate the interference of $\mathrm{K}^{+}$ ions, all samples were diluted 500-1000 times with MilliQ water.

\subsection{Cation exchange capacity procedure}

The method used for the determination of the cation exchange capacity was the one proposed by Munera-Echeverri et al. [19]. The procedure can be briefly summarized in three main steps: pretreatment, release of exchangeable cations in $\mathrm{NH}_{4} \mathrm{OAc}$, and substitution of $\mathrm{NH}_{4}{ }^{+}$by $\mathrm{K}^{+}$. In the first step, biochar samples were washed with water, and $\mathrm{pH}$ adjusted to pH 7 using $\mathrm{HCl} 50 \mathrm{mM}$. Next, biochar was washed three times with deionized water $\left(20 \mathrm{~mL}\right.$ of $\mathrm{H}_{2} \mathrm{O} / 1 \mathrm{~g}$ of solid) until conductivity values around $0.2 \mathrm{mS} / \mathrm{cm}$. In the second step, biochar was extracted two times with $\mathrm{NH}_{4} \mathrm{OAc} 1 \mathrm{M}$ solution (20 mL/1 g of solid). During the extraction, the sample was orbitally shaken for $24 \mathrm{~h}$ at $200 \mathrm{rpm}$ and the supernatant was collected after centrifugation at $1700 \mathrm{~g}$ for $20 \mathrm{~min}$. The supernatant was analyzed for base cations (CEC-BC) using the ICP MP-AES AGILENT 4200. The instrument was calibrated using a multi-element standard solution for ICP (TraceCERT®, Sigma-Aldrich).

In the last step, the excess of $\mathrm{NH}_{4} \mathrm{OAc}$ was removed by washing with isopropanol and subsequently the sample was incubated with a solution of $\mathrm{KCl} 2 \mathrm{M}(20 \mathrm{~mL} / 1 \mathrm{~g}$ of solid) to exchange $\mathrm{NH}_{4}{ }^{+}$with $\mathrm{K}^{+}$. The ammonium amount was quantified using two different approaches: ion chromatography (see Section 2.7) and a colorimetric method previously described in the literature [23, 24] with some modifications. Briefly, reagent A was prepared by dissolving $1.0 \mathrm{~g}$ of sodium salicylate and $0.1 \mathrm{~g}$ of sodium nitroprusside in $100 \mathrm{~mL}$ of citrate buffer (0.27 M trisodium citrate and $\mathrm{NaOH} 0.054 \mathrm{M}$ ). Reagent $\mathrm{B}$ was prepared by dilution of $2 \mathrm{~mL}$ of $6 \%$ sodium hypochlorite $(\mathrm{NaOCl})$ in $100 \mathrm{~mL}$ of water. A calibration curve was made, using standard solutions of $\mathrm{NH}_{4} \mathrm{Cl}$ containing $0,50,75,100$, 500 , and $1200 \mathrm{NH}_{4}^{+} \mu \mathrm{g} / \mathrm{L}$. Next, $0.5 \mathrm{~mL}$ of reagent A and B was added to $10-\mathrm{mL}$ plastic tubes containing $3 \mathrm{~mL}$ of the $\mathrm{KCl}$ $2 \mathrm{M}$ extracts of each sample diluted 1000 times with MilliQ water. The dilution was necessary to obtain a concentration of ammonium ion in the calibration range. The samples were shaken using an orbital shaker in the dark, and after $3 \mathrm{~h}$, the absorbance values were read at $655 \mathrm{~nm}$.

\section{Results and discussion}

\subsection{Biochar characterization}

Table 1 lists the humidity of the feedstocks (calculated following the procedure UNI EN ISO 18134-2) and the production yields.

As pyrolysis temperature increases, biochar yield decreases for all feedstocks, in agreement with the literature $[1,25]$ and experience. Instead, the type of feedstock does not have a remarkable influence on biochar yield in this lab-scale TGA experiments. The yields are comparable to those reported for similar systems in the literature [26].

Concerning the composition of obtained chars, the results of the elemental analysis carried out on biomasses and biochars are shown in Fig. 2 and in Table S1 in ESI file, while the ash and volatile content of the feedstocks and biochars are reported in Table S2 in ESI file. The values of elemental analysis and ash content are given in \% mass, dry basis $(\mathrm{wt} \%, \mathrm{db})$ while the volatile amounts are given in $\%$ mass, dry ash free (wt\%, daf).

The ash content is higher in the case of hardwoods (poplar and willow) compared to softwoods (black pine) both in the starting feedstocks and biochars. The amount of ash increases with increasing the pyrolysis temperature, and the willow is the biomass which produces more ash followed by poplar and black pine. The opposite trend is found for volatile content of the feedstocks, with black pine containing the highest amount of volatiles. All feedstocks contain about $6 \mathrm{wt} \%$ of hydrogen, while the amount of carbon is greater for pine (about $52 \mathrm{wt} \%$ ) compared to poplar and willow with about $49 \mathrm{wt} \%$.

As regards biochars, the process temperature influences the elemental composition. Higher temperatures lead to higher devolatilization and thus release of hydrogen and oxygen with a linear trend, while the carbon content shows an opposite trend (in percentage). Thus, the $\mathrm{H} / \mathrm{C}$ ratio decreases with increasing pyrolysis temperature as shown in Fig. 3a. A higher carbon content in the feedstock also leads to a more carbonaceous biochar (see pine char).

The sulfur content is equal to $0.01 \mathrm{wt} \%$ for pine and poplar feedstocks and remains constant even in chars produced at different temperatures. Willow contains $0.04 \mathrm{wt} \%$ of $\mathrm{S}$, 
Table 1 Feedstock humidity and biochar yields for the different samples: black pine (BP), poplar $(\mathrm{P})$, and willow (W)

\begin{tabular}{|c|c|c|c|c|c|c|c|c|c|c|c|}
\hline \multicolumn{3}{|c|}{ Feedstock humidity $\%$} & \multicolumn{3}{|c|}{$400{ }^{\circ} \mathrm{C}$ (yield*) } & \multicolumn{3}{|c|}{$550{ }^{\circ} \mathrm{C}$ (yield*) } & \multicolumn{3}{|c|}{$650{ }^{\circ} \mathrm{C}$ (yield*) } \\
\hline $\mathrm{BP}$ & $\mathrm{P}$ & $\mathrm{W}$ & $\mathrm{BP}$ & $\mathrm{P}$ & $\mathrm{W}$ & $\mathrm{BP}$ & $\mathrm{P}$ & W & $\mathrm{BP}$ & $\mathrm{P}$ & $\mathrm{W}$ \\
\hline 28.5 & 39.4 & 40.2 & 29.6 & 29.9 & 29.2 & 19.6 & 19.7 & 21.2 & 17.9 & 18.7 & 16.9 \\
\hline
\end{tabular}

*The values of the yields are given in $\%$ mass, dry basis (wt $\%, \mathrm{db}$ ) slightly increasing in biochars produced at 400 and $550{ }^{\circ} \mathrm{C}$ up to $0.06 \mathrm{wt} \%$ as a consequence of the biomass conversion.

Figure $3 \mathrm{~b}$ shows the high values of the $\mathrm{C} / \mathrm{N}$ ratio obtained for all the analyzed samples. This parameter is generally used to predict the exchange and retention of nitrogen in soil: high $\mathrm{C}$ / $\mathrm{N}$ values lead to rapid nitrogen immobilization which in turns avoid nitrogen leaching in the soil and its volatilization [27].

However, the $\mathrm{C} / \mathrm{N}$ ratio is not the only relevant parameter, as variations of soil temperature and humidity can also affect theactual $\mathrm{C} / \mathrm{N}$ ratio stimulating or inhibiting the microbial activity [28].

The main functional groups of the different samples can be evidenced from the IR spectra showed in Fig. 4 panel a while Fig. 4 panel $b$ reports how the surface area obtained through nitrogen adsorption isotherms changes as a function of the production temperature.

The spectra of feedstocks obviously differ from those of biochars, and the effect of pyrolysis temperature is also evident. The most remarkable change in the char spectra, compared to feedstocks, is the disappearance of the band at around $3400 \mathrm{~cm}^{-1}$ ascribed to the $\mathrm{O}-\mathrm{H}$ stretching of the hydroxyl groups in cellulose and hemicellulose and hydration water. The same effect is observed for the signals of hemicellulose and cellulose $\mathrm{C}-\mathrm{H}$ stretching located at $3000-2800 \mathrm{~cm}^{-1}$. This behavior can be explained as a result of the pyrolysis process [29, 30]. The signal observed at around $1650 \mathrm{~cm}^{-1}$ is clearly visible in the char produced at $400{ }^{\circ} \mathrm{C}$ : it is associated to the carboxyl groups of hemicellulose, and its intensity decreases as the pyrolysis temperature increases as a consequence of the thermal decomposition of these groups. The evolution of the infrared spectra associated to the gradual removal of oxygen-containing species is in good agreement with the findings from the elemental analysis of the chars (Fig. 2). In addition, the samples produced at high temperatures $\left(550\right.$ and $650{ }^{\circ} \mathrm{C}$ ) show the appearance of two new signals in the region $1000-1100 \mathrm{~cm}^{-1}$ and $1300-1500 \mathrm{~cm}^{-1}$ probably ascribable to the presence of $\mathrm{C}-\mathrm{O}$ and $\mathrm{C}=\mathrm{O}$ groups from ether-like and ketone-like species [31, 32], which are less evident for the char produced starting from black pine feedstock. The decomposition of cellulose, hemicellulose, and lignin is also confirmed by the disappearing of the prominent band centered at around $1000 \mathrm{~cm}^{-1}$ in the spectra of the feedstocks, which is assigned to $\mathrm{C}-\mathrm{O}$ and $\mathrm{C}-\mathrm{C}$ stretching or $\mathrm{C}-\mathrm{OH}$ bending [33].
Fig. 2 Elemental analysis of biochars obtained at different temperatures and from diverse starting feedstocks

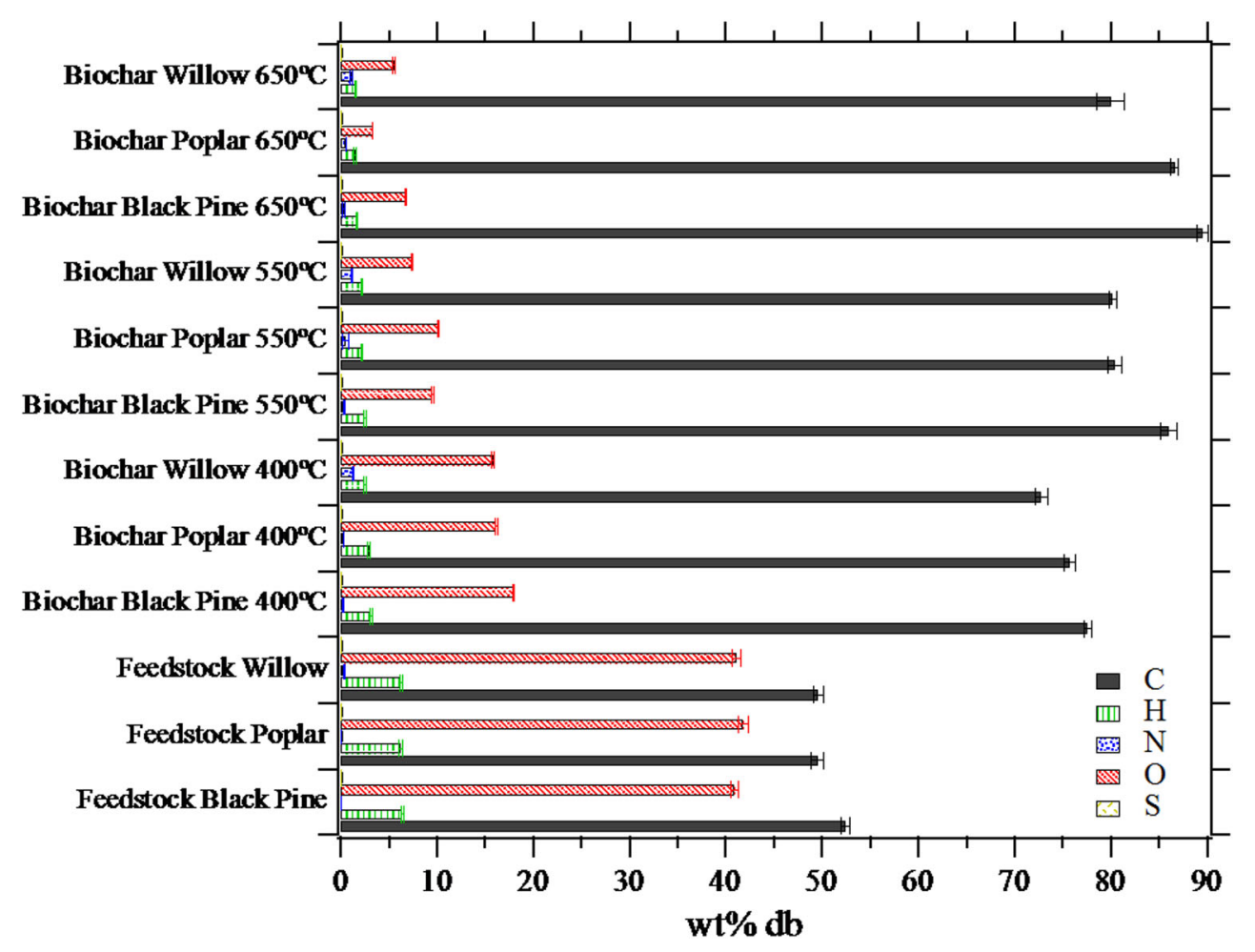



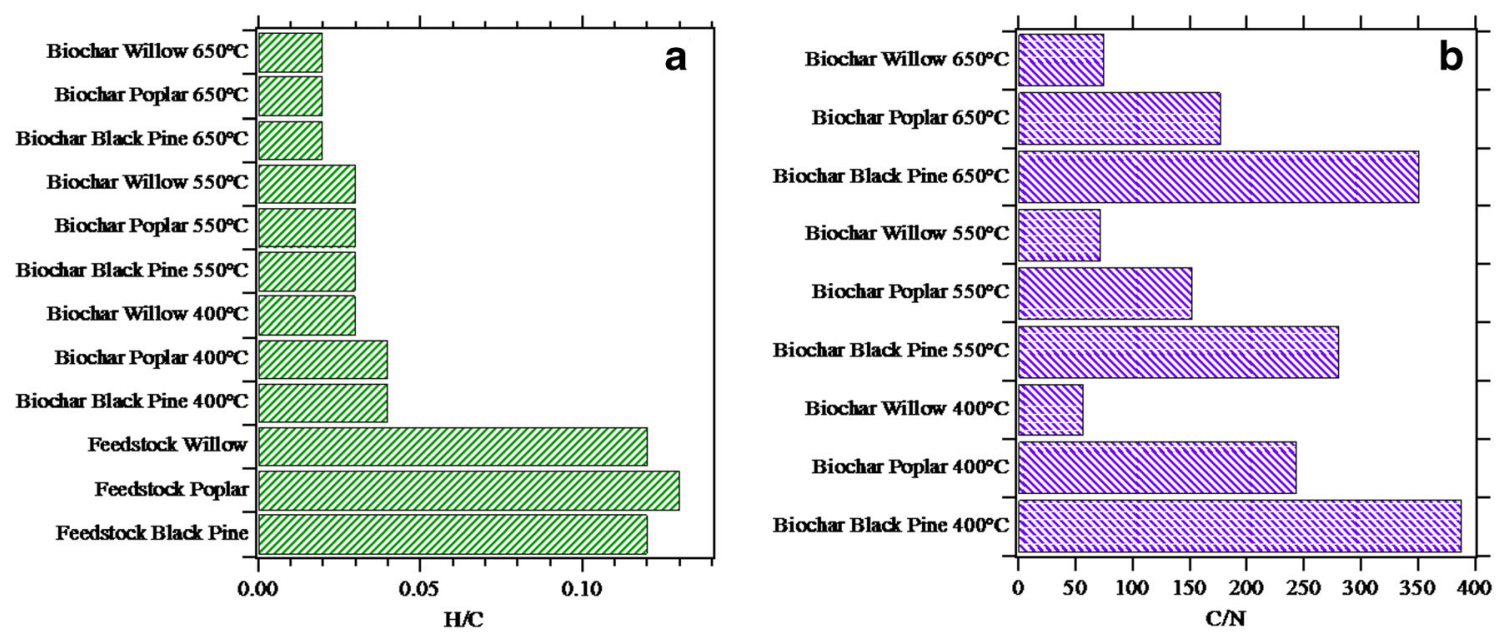

Fig. $3 \mathrm{H} / \mathrm{C}$ ratio (panel a) and $\mathrm{C} / \mathrm{N}$ ratio (panel b) for biochars obtained at different temperatures and from diverse feedstocks

The bands associated with the aromatic $\mathrm{C}=\mathrm{C}$ stretching $\left(1440 \mathrm{~cm}^{-1}\right)$ are clearly visible in biochars' spectra, and their intensity increases as the working temperature passes from 400 to $650{ }^{\circ} \mathrm{C}$ as a further confirmation of the graphitization process [34].

The surface area and pore volume of chars are among the most important features affecting the adsorption and retention properties of these materials. Biochars with high surface area can thus be obtained at higher $\mathrm{T}$ (see Fig. 4 panel b). This result is consistent with the work of McLaughlin et al. [35], where the increase in the surface area at temperatures above $300{ }^{\circ} \mathrm{C}$ can be associated to the development of turbostratic regions inside the char with a structural organization between that of amorphous and crystalline carbon, as the solid enriches in carbon content [1]. However, they demonstrated that above $700{ }^{\circ} \mathrm{C}$ the surface area tends to decrease due to the "calcination" of the graphene residues with the consequent coalescence in denser, less porous structures.

The effect of high temperatures on surface area is more evident for pine biochar, which shows the largest BET area $\left(504 \mathrm{~m}^{2} / \mathrm{g}\right)$ at $550^{\circ} \mathrm{C}$. This is in good agreement with previous literature, where it is reported that biochar obtained from coniferous lignocellulosic biomass is characterized by a greater surface area if compared to deciduous equivalents [36].

The adsorption isotherms of the biochars at the different pyrolysis temperatures (see Fig. S1 in the Supplementary Material file) show a hysteresis, indicating the co-presence of micro- and mesopores in all samples [37]. By using the DFT approach, the micro-pore size distribution was estimated, as reported in Fig. 5 panel a, while Fig. 5 panel b reports the macro-pore distribution obtained from $\mathrm{Hg}$ porosimeter on the biochars produced at $550{ }^{\circ} \mathrm{C}$.

The micro-porosity of the chars produced at $400{ }^{\circ} \mathrm{C}$ is in the range between 1 and $10 \mathrm{~nm}$, with no clear differences in pore size distribution for the different feedstocks. By increasing the carbonization temperature, pore sizes in the range of 1 to $8 \mathrm{~nm}$ for black pine were observed, showing the highest micro-porosity in good accordance with the greater surface area found for pine biochar.

Regarding macro-porosity of biochars produced at $550^{\circ} \mathrm{C}$, poplar and willow biochars possess pores in the range between 0.5 and $500 \mu \mathrm{m}$ with a small population centered at around $1 \mu \mathrm{m}$. Differently, the pore distribution for pine char shows a pronounced maximum at around $10 \mu \mathrm{m}$ together with
Fig. 4 Panel a FTIR spectra of black pine, poplar, willow biochars produced at different pyrolysis temperatures $\left(400^{\circ} \mathrm{C}\right.$, $550{ }^{\circ} \mathrm{C}$, and $650{ }^{\circ} \mathrm{C}$ ), and from diverse initial feedstocks. Curves are offset along $y$-axis. Panel b Surface area from nitrogen adsorption measured on black pine (circles), poplar (squares), and willow (triangles) biochars at different pyrolysis temperatures. In the case of $400{ }^{\circ} \mathrm{C}$, error bars are comparable to the marker size
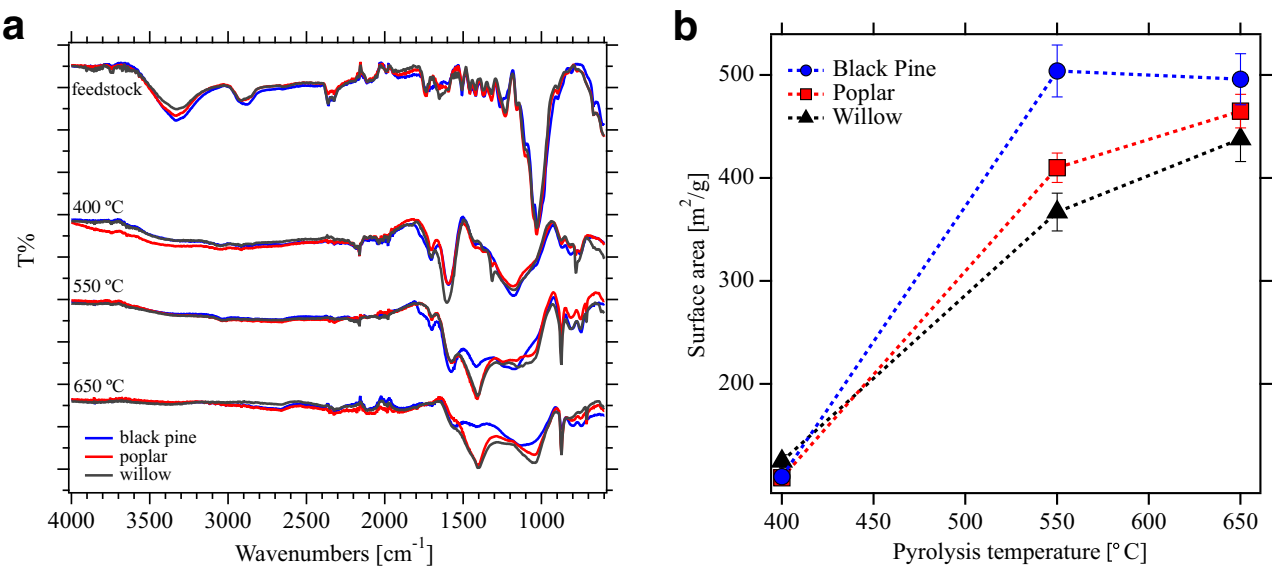
Fig. 5 Micro- (panel a, left) and macro-porosity (panel $\mathbf{b}$, right) obtained from nitrogen and $\mathrm{Hg}$ porosimetry, respectively

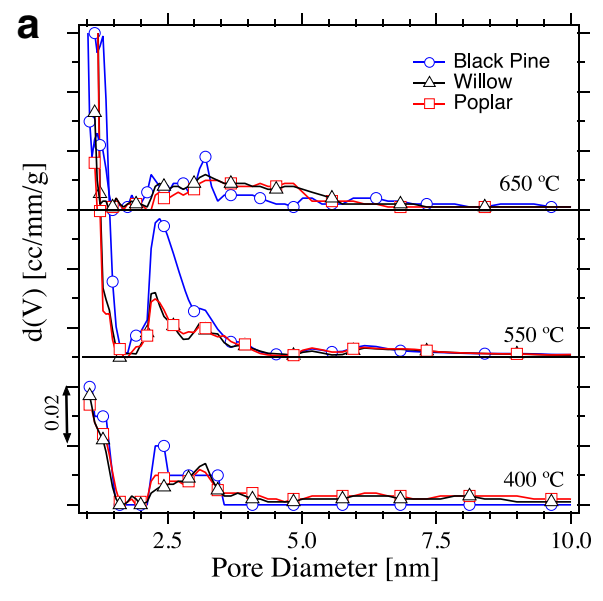

larger pores with a diameter around $200 \mu \mathrm{m}$. The observed differences in the macro-porosity measured for the three chars suggest a strong dependence of this parameter on the morphological structure of the feedstock, as already known in the literature [37]. A further confirmation of the presence of macropores in the samples comes from scanning electron micrographs reported in Fig. 6.

From $\mathrm{Hg}$ porosimetry, it is possible to obtain also the values of density associated to the different samples. In

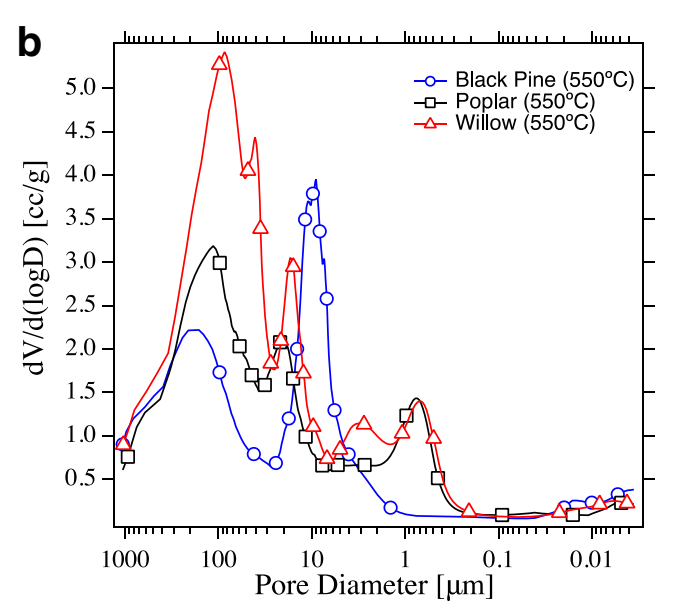

Fig. 7 the density of the samples versus the surface area obtained from BET analysis is reported.

Observing Fig. 7, it is interesting to note that willow biochar has the highest macro-porosity (i.e., lowest density) and the lowest surface area. This result might be counterintuitive; however, it can be rationalized considering that the surface area mainly depends on the micro-porosity, while the density is mainly a function of the macro-porosity of the starting biomass. From the obtained data, we can conclude that willow
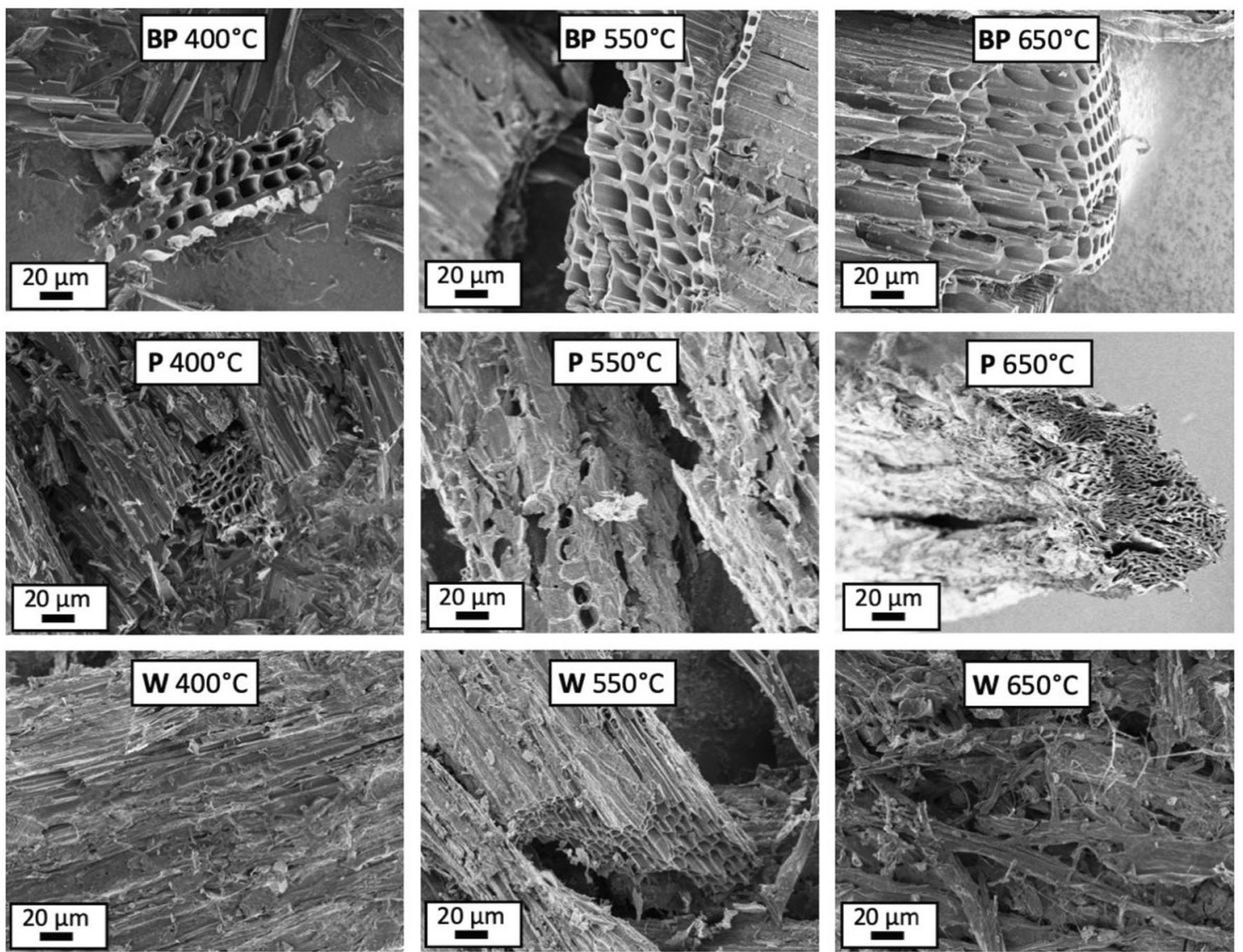

Fig. 6 Scanning electron micrographs at the same magnification $(1 \mathrm{kX})$ of black pine $(\mathrm{BP})$, poplar $(\mathrm{P})$, and willow (W) biochars obtained at different pyrolysis temperatures 


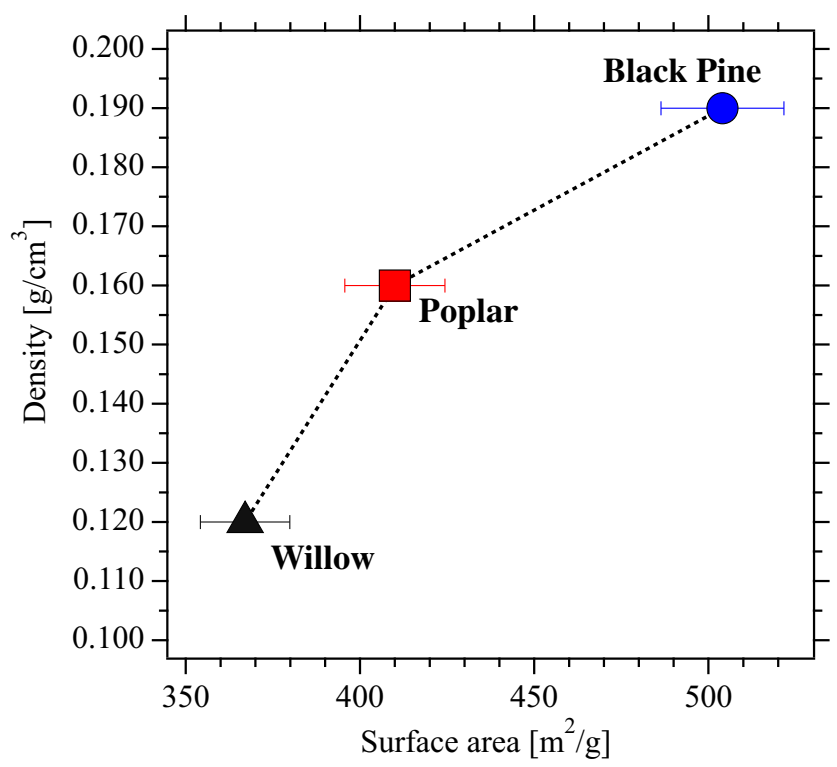

Fig. 7 Density values (from $\mathrm{Hg}$ porosimetry) vs surface area (BET) for the char samples prepared at $550^{\circ} \mathrm{C}$

biochar could be the best for retaining water and making it available for the plants. Indeed, it was demonstrated that pores in the nanometric size range are not relevant for water release in the soil because plants are unable to overcome the high capillary forces of water confined in small pores [38].

\subsection{Cation exchange capacity}

CEC was evaluated on the biochars also by measuring the CEC-BC. In the work by Munera-Echeverri et al. [19], remarkable differences between $\mathrm{CEC}-\mathrm{NH}_{4}$ and $\mathrm{CEC}-\mathrm{BC}$ were found, with $\mathrm{CEC}-\mathrm{NH}_{4} / \mathrm{CEC}-\mathrm{BC}$ ratios in the range 1.0-4.0.

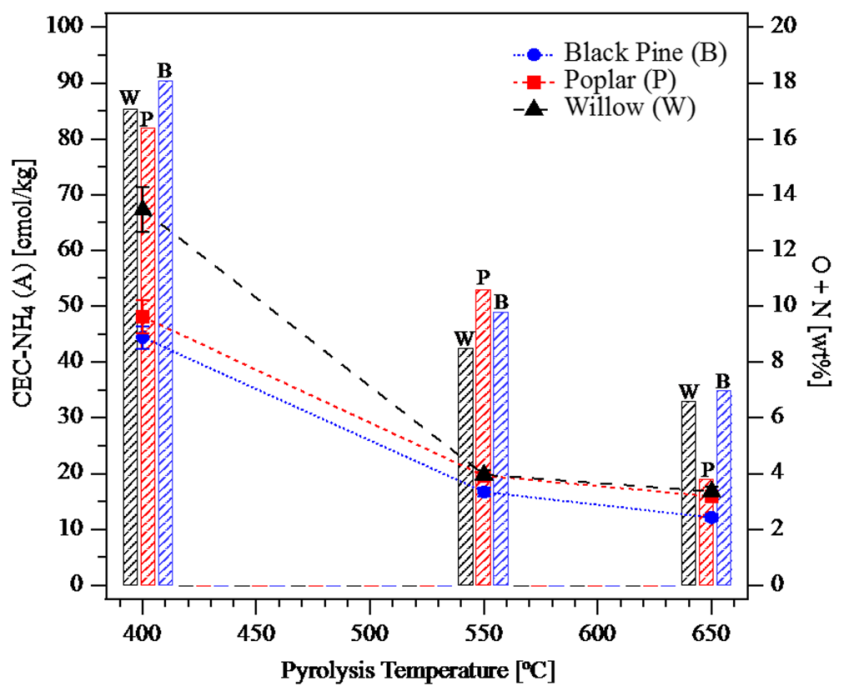

Fig. 8 CEC-NH $\mathrm{NH}_{4}$ (markers) and oxygen + nitrogen amounts (bars) obtained from black pine (B, blue), poplar ( $\mathrm{P}$, red), and willow (W, black) biochars produced at different pyrolysis temperatures. In the case of 550 and $650^{\circ} \mathrm{C}$, error bars are comparable to the marker size
The discrepancies between these two methods were ascribed to the fact that isopropanol, used as washing agent, does not effectively remove $\mathrm{NH}_{4}{ }^{+}$trapped in the small pores of biochar, presumably due to the size of isopropanol molecules which cannot penetrate in these cavities.

The concentrations of the base cations extracted from the biochar samples are listed in Table S3 and S4 in ESI file while Table 2 reports the CEC-NH $\mathrm{N}_{4}$ obtained by the quantification of ammonium from ion chromatography (A) and colorimetric method (B). Both readily soluble cations and exchangeable cations after washing with ammonium acetate are considered. It has to be underlined that the concentrations of $\mathrm{Fe}^{3+}, \mathrm{Al}^{3+}$, and $\mathrm{Mn}^{2+}$ ions are very low in all the analyzed biochar (Table S4) and thus they are not considered to calculate the $\mathrm{CEC}-\mathrm{BC}$ values.

The observed CEC-NH $\mathrm{NH}_{4}$ values (as summarized in Fig. 8) indicate that poplar and willow biochars obtained at $400{ }^{\circ} \mathrm{C}$ exchange more cations than the corresponding product obtained from pine wood. The lowest $\mathrm{CEC}-\mathrm{NH}_{4}$ value is obtained for black pine char produced at processing temperature above $400{ }^{\circ} \mathrm{C}$. Considering that this sample possesses the highest surface area, this result suggests that the surface area is not the main factor involved in the exchange of ions with the environment. Furthermore, the highest CEC values are observed for chars produced at pyrolysis temperature of $400{ }^{\circ} \mathrm{C}$, which are the samples with the lowest surface area if compared to the samples produced at $550{ }^{\circ} \mathrm{C}$ and $650{ }^{\circ} \mathrm{C}$.

The observed behavior can be therefore explained considering also the effect of high temperature on the polar functional groups on chars' surface. In fact, the increase of temperature leads to a decrease of polar components as evidenced by the percentage of oxygen + nitrogen reported in Fig. 8. This evidence indicates that CEC is mainly controlled by the rate at which the polar groups are removed rather than the new surface area formed increasing the pyrolysis temperature. Among the exchangeable cations, $\mathrm{Ca}^{2+}$ shows the highest tendency to be exchanged, especially from poplar and willow biochar obtained at a temperature of $550{ }^{\circ} \mathrm{C}$.

In conclusion, we can summarize that the $\mathrm{CEC}$ values depend on two different parameters, temperature of pyrolysis, and starting feedstock.

- Pyrolysis temperature: the increase of the temperature leads to an increase of the surface area and a gradual removal of polar species ( $\mathrm{O}$ and $\mathrm{N})$. Probably, the decrease of polar compounds in the sample might be connected to the decrease of the CEC value.

- Starting feedstock: considering the biochars produced at the same temperature, the CEC values depend on the starting feedstock. In particular, we observed that black pine biochars possess the lowest CEC values even if they are characterized by higher surface area and higher 
Table 2 CEC-NH ${ }_{4}$ obtained from ion chromatography (A) and colorimetric method (B). The values in parentheses are the standard deviation on the last significant figure

\begin{tabular}{|c|c|c|c|c|c|c|c|c|c|}
\hline \multirow[t]{2}{*}[\mathrm{cmol}(+)/\mathrm{kg}]{} & \multicolumn{3}{|c|}{$400{ }^{\circ} \mathrm{C}$} & \multicolumn{3}{|l|}{$550{ }^{\circ} \mathrm{C}$} & \multicolumn{3}{|l|}{$650^{\circ} \mathrm{C}$} \\
\hline & BP & $\mathrm{P}$ & W & $\mathrm{BP}$ & $\mathrm{P}$ & W & BP & $\mathrm{P}$ & W \\
\hline CEC-NH 4 (A) & $44(2)$ & $48(3)$ & $67(4)$ & $16.7(8)$ & $19.6(9)$ & $19.8(9)$ & $12.1(6)$ & $15.9(8)$ & $16.8(9)$ \\
\hline CEC-NH ${ }_{4}(\mathrm{~B})$ & $45(4)$ & $52(3)$ & $65(5)$ & $20(2)$ & $20(1)$ & $23(2)$ & $12(1)$ & $17(1)$ & $18(1)$ \\
\hline
\end{tabular}

amounts of polar components. This behavior can be explained considering that black pine chars exhibit the presence of pores in the nanometric size range that are not relevant for water exchange due to the high capillary forces.

\section{Conclusions}

The aim of this study is to investigate at lab-scale the relationship between the physical-chemical properties of the obtained biochars and the production conditions, such as the biomass feedstock and the pyrolytic temperature. Nine biochars were pyrolyzed at 400,550 , and $650{ }^{\circ} \mathrm{C}$ from three different biomasses (black pine, poplar, and willow), selected from both hard and softwood. Here the combined use of nitrogen adsorption isotherm, $\mathrm{Hg}$ porosimetry, electron microscopy, and evaluation of the cation exchange capacity is proposed to correlate the properties of the char with the production condition and starting biomass.

The results indicate that biochars with high surface area can be obtained at high $\mathrm{T}$, and this effect is more evident for pine biochar, which shows the largest surface area $\left(504 \mathrm{~m}^{2} / \mathrm{g}\right)$ at $550{ }^{\circ} \mathrm{C}$. The pore analysis evidences that chars are characterized by two different types of pores: micro-pores in the range between 1 and $10 \mathrm{~nm}$ that are not remarkably affected by the starting feedstocks, together with macro-pores whose size is strongly dependent on the morphological structure of the initial wood type. Indeed, poplar and willow samples pyrolyzed at $550{ }^{\circ} \mathrm{C}$ possess pores in the range between 0.5 and $500 \mu \mathrm{m}$, with a small population centered at around $1 \mu \mathrm{m}$, while pore distribution for pine char shows a maximum at around $10 \mu \mathrm{m}$ together with larger pores with a diameter around $200 \mu \mathrm{m}$.

Regarding the retention/release properties of the investigated samples, our studiesdemonstrate that poplar and willow biochars exchange more cations than the corresponding product obtained from black pine wood. This behavior can be explained considering that black pine chars exhibit the presence of pores in the nanometric size range that are not relevant for water exchange due to the high capillary forces. Furthermore, we also note that the highest CEC values are observed for chars produced at pyrolysis temperature of $400{ }^{\circ} \mathrm{C}$, which are the samples with the lowest surface area if compared to the samples produced at $550{ }^{\circ} \mathrm{C}$ and $650{ }^{\circ} \mathrm{C}$. This finding suggests an effect of the temperature on the final properties of these materials: indeed, the increase of the pyrolysis temperature leads to a gradual removal of polar species and, consequently, a decrease of the CEC is observed for the samples produced at $550{ }^{\circ} \mathrm{C}$ and $650{ }^{\circ} \mathrm{C}$. To summarize, the CEC, which is a very important parameter when char is employed for soil applications, seems to be mainly dependent on the amount of polar component on their surface. The effect of chars' surface area has to be considered as well.

This study aims at representing a step forward in the characterization of the char produced by pyrolysis of biomass. Although previous reports investigated biochars produced from different biomasses at different pyrolysis temperatures, they only dealt with the water retention [20] or the mechanical properties [21] of the obtained chars without focusing on the CEC. On the other hand, works reporting the measure of the CEC for different chars did not provide an exhaustive characterization of the carbonaceous material [15, 18, 19] as in the present study.

Here, we propose a multi-technique approach for a complete characterization of the carbonaceous substrates in terms of chemical composition, morphology, and porosity as a function of the starting wood type and pyrolysis temperature. In addition, we report on an optimized methodology for the evaluation of the CEC in order to give an insight on the structure-property correlation of the biochars. This experimental approach can be used to gain additional information on the CEC capacity of the chars helping in the optimization of the parameters used in the preparation of these materials. However, this work is based on TGA labscale pyrolysis: further analysis with slow pyrolysis carried out at pilot or demo scale will be needed, as biochars obtained in pilot reactors are expected to be different from those obtained in TGA. Moreover, other parameters will heavily impact on the product characteristics, namely reactor design and solid residence time.

Supplementary Information The online version contains supplementary material available at https://doi.org/10.1007/s13399-021-01303-5.

Acknowledgments The authors wish to acknowledge Dr. Mirko Severi (University of Florence) for the help in the CEC 
determination by ion chromatography and Silvia Pennazzi and Giulia Lotti from RE-CORD laboratory for their contribution to the analytical work on feedstocks and products.

Author Contributions David Chiaramonti, Emiliano Fratini, Luca Rosi: conceptualization.

Andrea Maria Rizzo, Lorenzo Bettucci, David Casini, Giovanni Ferraro, Emiliano Fratini, Giuditta Pecori: formal analysis.

Giovanni Ferraro, Emiliano Fratini, Giuditta Pecori, Luca Rosi: data curation.

Giovanni Ferraro, Emiliano Fratini, Luca Rosi: writing —original draft preparation.

Lorenzo Bettucci, Giovanni Ferraro, Emiliano Fratini, Giuditta Pecori, Luca Rosi: methodology.

David Chiaramonti, Giovanni Ferraro, Emiliano Fratini, Luca Rosi: writing - review and editing.

Funding Open Access funding provided by Università degli Studi di Firenze within the CRUI-CARE Agreement. GF, GP, LR, and EF acknowledge "Progetto Dipartimenti di Eccellenza 2018-2022" allocated to Department of Chemistry 'Ugo Schiff' from MIUR, for financial support. GF and EF kindly acknowledge partial financial support from Consorzio per lo sviluppo dei Sistemi a Grande Interfase (CSGI).

\section{Compliance with ethical standards}

Competing interests The authors declare that they have no competing interests.

Open Access This article is licensed under a Creative Commons Attribution 4.0 International License, which permits use, sharing, adaptation, distribution and reproduction in any medium or format, as long as you give appropriate credit to the original author(s) and the source, provide a link to the Creative Commons licence, and indicate if changes were made. The images or other third party material in this article are included in the article's Creative Commons licence, unless indicated otherwise in a credit line to the material. If material is not included in the article's Creative Commons licence and your intended use is not permitted by statutory regulation or exceeds the permitted use, you will need to obtain permission directly from the copyright holder. To view a copy of this licence, visit http://creativecommons.org/licenses/by/4.0/.

\section{References}

1. Lehmann J, Joseph S (2015) Biochar for environmental management: science, technology and implementation. Routledge

2. Abdelhafez AA, Abbas MH, Li J (2017) Biochar: the black diamond for soil sustainability, contamination control and agricultural production. Engineering Applications of Biochar 2. https://doi.org/ 10.5772/intechopen.68803

3. Suliman W, Harsh JB, Abu-Lail NI, Fortuna AM, Dallmeyer I, Garcia-Pérez M (2017) The role of biochar porosity and surface functionality in augmenting hydrologic properties of a sandy soil. Sci Total Environ 574:139-147. https://doi.org/10.1016/j.scitotenv. 2016.09.025

4. Abdelhafez AA, Li J (2016) Removal of Pb (II) from aqueous solution by using biochars derived from sugar cane bagasse and orange peel. J Taiwan Inst Chem Eng 61:367-375. https://doi.org/ 10.1016/j.jtice.2016.01.005

5. Hassan M, Liu Y, Naidu R et al (2020) Influences of feedstock sources and pyrolysis temperature on the properties of biochar and functionality as adsorbents: a meta-analysis. Sci Total Environ 140714
6. McKenzie N, Jacquier D, Isbell R, Brown K (2004) Australian soils and landscapes: an illustrated compendium. CSIRO publishing

7. Tan Z, Yuan S, Hong M, Zhang L, Huang Q (2020) Mechanism of negative surface charge formation on biochar and its effect on the fixation of soil Cd. J Hazard Mater 384:121370. https://doi.org/10. 1016/j.jhazmat.2019.121370

8. Edeh IG, Mašek O, Buss W (2020) A meta-analysis on biochar's effects on soil water properties-new insights and future research challenges. Sci Total Environ 714:136857

9. Omondi MO, Xia X, Nahayo A, Liu X, Korai PK, Pan G (2016) Quantification of biochar effects on soil hydrological properties using meta-analysis of literature data. Geoderma 274:28-34

10. Lei O, Zhang R (2013) Effects of biochars derived from different feedstocks and pyrolysis temperatures on soil physical and hydraulic properties. J Soils Sediments 13:1561-1572. https://doi.org/10. 1007/s11368-013-0738-7

11. Hardy B, Sleutel S, Dufey JE, Cornelis J-T(2019) The long-term effect of biochar on soil microbial abundance, activity and community structure is overwritten by land management. Frontiers in Environmental Science 7:110. https://doi.org/10.3389/fenvs.2019. 00110

12. Zheng W, Sharma BK, Rajagopalan N (2010) Using biochar as a soil amendment for sustainable agriculture. Resource Recovery> Biochar

13. Rawat J, Saxena J, Sanwal P (2019) Biochar: a sustainable approach for improving plant growth and soil properties. In: Biochar-An Imperative Amendment for Soil and the Environment. IntechOpen

14. Bolt GH, Bruggenwert MGM, Kamphorst A (1976) Adsorption of cations by soil. In: Developments in Soil Science. Elsevier, pp. 54 90

15. Chapman HD (1965)Cation-exchange capacity. Methods of soil analysis: part 2 chemical and microbiological properties 9:891-901

16. Ross DS, Ketterings Q (1995) Recommended methods for determining soil cation exchange capacity. Recommended soil testing procedures for the northeastern United States 2:62-70

17. Gillman GP, Sumpter EA (1986) Modification to the compulsive exchange method for measuring exchange characteristics of soils. Soil Research 24:61-66. https://doi.org/10.1071/sr9860061

18. Graber ER, Singh B, Hanley K, Lehmann J (2017) Determination of cation exchange capacity in biochar. Biochar: A Guide to Analytical Methods 74-84

19. Munera-Echeverri JL, Martinsen V, Strand LT, Zivanovic V, Cornelissen G, Mulder J (2018) Cation exchange capacity of biochar: an urgent method modification. Sci Total Environ 642:190 197. https://doi.org/10.1016/j.scitotenv.2018.06.017

20. Kameyama K, Miyamoto T, Iwata Y (2019) The preliminary study of water-retention related properties of biochar produced from various feedstock at different pyrolysis temperatures. Materials 12: 1732. https://doi.org/10.3390/ma12111732

21. Das O, Sarmah AK, Bhattacharyya D (2015)Structure-mechanics property relationship of waste derived biochars. Sci Total Environ 538:611-620. https://doi.org/10.1016/j.scitotenv.2015.08.073

22. Ravikovitch PI, Haller GL, Neimark AV (1998) Density functional theory model for calculating pore size distributions: pore structure of nanoporous catalysts. Adv Colloid Interf Sci 76:203-226. https:// doi.org/10.1016/S0001-8686(98)00047-5

23. Ottaviani M, Bonadonna L (2007) Metodi analitici di riferimento per le acque destinate al consumo umano ai sensi del DL. vo 31/ 2001. Metodi chimici. RAPPORTI ISTISAN 31:

24. Bower CE, Holm-Hansen T (1980) A salicylate-hypochlorite method for determining ammonia in seawater. Can J Fish Aquat Sci 37:794-798

25. Poletto M, Zattera AJ, Forte MM, Santana RM (2012) Thermal decomposition of wood: influence of wood components and 
cellulose crystallite size. Bioresour Technol 109:148-153. https:// doi.org/10.1016/j.biortech.2011.11.122

26. Kan T, Strezov V, Evans TJ (2016) Lignocellulosic biomass pyrolysis: a review of product properties and effects of pyrolysis parameters. Renew Sust Energ Rev 57:1126-1140

27. Prasad MNV, Shih K (2016) Environmental materials and waste: resource recovery and pollution prevention. Academic Press

28. Bengtsson G, Bengtson P, Mansson KF (2003) Gross nitrogen mineralization-, immobilization-, and nitrification rates as a function of soil $\mathrm{C} / \mathrm{N}$ ratio and microbial activity. Soil Biol Biochem 35: 143-154. https://doi.org/10.1016/S0038-0717(02)00248-1

29. Brewer CE, Schmidt-Rohr K, Satrio JA, Brown RC (2009) Characterization of biochar from fast pyrolysis and gasification systems. Environmental Progress \& Sustainable Energy: An Official Publication of the American Institute of Chemical Engineers 28:386-396. https://doi.org/10.1002/ep.10378

30. Jouiad M, Al-Nofeli N, Khalifa N et al (2015) Characteristics of slow pyrolysis biochars produced from Rhodes grass and fronds of edible date palm. J Anal Appl Pyrolysis 111:183-190. https://doi. org/10.1016/j.jaap.2014.10.024

31. Acik M, Lee G, Mattevi C, Chhowalla M, Cho K, Chabal YJ (2010) Unusual infrared-absorption mechanism in thermally reduced graphene oxide. Nat Mater 9:840-845

32. Mittal G, Rhee KY, Park SJ, Hui D (2017) Generation of the pores on graphene surface and their reinforcement effects on the thermal and mechanical properties of chitosan-based composites. Compos Part B 114:348-355

33. Peng F, Ren J-L, Xu F, Bian J, Peng P, Sun RC (2010) Fractional study of alkali-soluble hemicelluloses obtained by graded ethanol precipitation from sugar cane bagasse. J Agric Food Chem 58: $1768-1776$

34. Cantrell KB, Hunt PG, Uchimiya M, Novak JM, Ro KS (2012) Impact of pyrolysis temperature and manure source on physicochemical characteristics of biochar. Bioresour Technol 107:419428

35. McLaughlin H, Anderson PS, Shields FE, Reed TB All biochars are not created equal, and how to tell them apart. Proceedings, North American Biochar Conference, Boulder, Colorado 1-36

36. Mukherjee A, Zimmerman AR, Harris W (2011) Surface chemistry variations among a series of laboratory-produced biochars. Geoderma 163:247-255. https://doi.org/10.1016/j.geoderma.2011. 04.021

37. Brewer CE, Chuang VJ, Masiello CA, Gonnermann H, Gao X, Dugan B, Driver LE, Panzacchi P, Zygourakis K, Davies CA (2014) New approaches to measuring biochar density and porosity. Biomass Bioenergy 66:176-185. https://doi.org/10.1016/j. biombioe.2014.03.059

38. Liu Z, Dugan B, Masiello CA, Gonnermann HM (2017) Biochar particle size, shape, and porosity act together to influence soil water properties. PLoS One 12:e0179079. https://doi.org/10.1371/ journal.pone.0179079

Publisher's NotePublisher's Note Springer Nature remains neutral with regard to jurisdictional claims in published maps and institutional affiliations. 